\title{
A Comparison Of Perceptions: Students And Bankruptcy Filers On Causes Of Financial Distress
}

\author{
Eugene M. Bland, (E-mail: eugene.bland@tamucc.edu), Texas A\&M University, Corpus Christi \\ J. Roberto A. deMagalhaes, (E-mail: roberto.demagalhaes@mail.business.und.edu), University of North Dakota \\ Pamela P. Stokes, (E-mail: pstokes@tamucc.edu), Texas A\&M University, Corpus Christi
}

\begin{abstract}
This study compares opinions about the causes of bankruptcy held by students at Texas A\&M University -Corpus Christi with those of individuals who have filed for Chapter 13 bankruptcy. Personal bankruptcy affects many Americans and is the source of much controversy. This study should be helpful to creditors, who need to avoid losses from unpaid debts, educators who must be aware of students' perceptions and misperceptions to effectively teach financial management, and legislators who pass laws on bankruptcy and related topics. Attorneys, accountants, and other financial advisors also need to be aware of signals of financial trouble in their clients.
\end{abstract}

\section{INTRODUCTION}

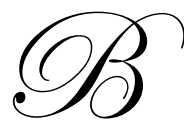

ankruptcy filings have been increasing, and in 2005, an estimated $\$ 40$ billion in debt was discharged via the bankruptcy process. Changes in the bankruptcy laws in October of 2005 will probably result in more people filing for Chapter 13 bankruptcy protection in the future. Therefore, more needs to be known about these individuals and what caused them to file for bankruptcy. The remainder of this paper is organized in the following manner. The next section describes past research and the relevant literature. We then describe the research methodology used, followed by the results of our survey. The conclusion summarizes our findings and their implications.

\section{RESEARCH}

A study by deMagalhaes and Stokes (2005) cited numerous articles and studies that attempted to identify the causes of bankruptcy, which we will summarize here. The most likely causes of bankruptcy are high medical expenses, divorce, or loss of a job (Ian Domwitz and Robert L. Sartain, 1999, J. J. Watson, 1998). People who declare bankruptcy also tend to have a high level of credit card and unsecured debt (Jean Clements et al. 1999, Ian Domwitz and Robert L. Sartain 1999). Khasru (1996) noted that difficulty making mortgage payments caused bankruptcies for low and middle-income homeowners, and that people who lose their jobs often begin to charge everyday expenses on credit cards in order to make their house payments. The results of the deMagalhaes and Stokes study corroborated the causes for bankruptcy that have been identified in the literature.

Regarding the motivations for materialism and overspending, and how they relate to happiness, Americans earned twice as much in 1996 as they did in 1957, but the proportion of persons surveyed identifying themselves as "very happy" declined from 35 to 29 percent (David G Myers and E Diener 1996). Robert Arkin's study, as reported by Beckman (2002), found that undergraduate students who are self-doubters compensate for their negative feelings by investing in material things. Arkin's research suggests a link between lower levels of satisfaction and materialism. Watson (1998) found that people who thought positively about debt and spending also had high levels of materialism. Watson's study did not, however, measure the relationship between materialism and actual debt. Logically, however, a relationship exists between high levels of materialism and overspending and resulting levels of indebtedness and financial difficulties. 
Bankruptcy expert Elizabeth Warren, focuses on the fragile financial situation of many American middleclass families. Her recently co-authored book (Warren and Tyagi 2003) contends that two-income families are more likely to file for bankruptcy than one-income families, and states that the incomes of these families are usually spent on necessities, rather than on unnecessary luxuries as many would suppose. The authors believe these families often buy expensive houses in order to live in neighborhoods with access to better schools. As a result, they are financially overextended and have no buffer to protect them when an unexpected emergency occurs. However, as deMagalhaes and Stokes note, many families do avoid such pitfalls and handle their financial matters in a different way. The results of the latter study, combined with those of this one, may help discover what factors are predictive of an individual's ability to handle money, and therefore that person's future financial success or failure.

As the current project focuses on residents of South Texas, previous studies of debtors in this state are pertinent. Past studies of consumer debt education programs in this geographic area suggest that debtors can be taught effective financial management skills and behaviors. Stokes (1995) indicated that over 80 percent of Chapter 13 debtors incorporated information presented in a debtor education class into their personal financial management activities. Thirty five percent indicated that their money management skills had improved "very much," while another 45 percent indicated that those skills improved "somewhat." Fifty seven percent of respondents chose the budgeting section of the course as most valuable, while 36 percent indicated "goal setting" was most valuable. Stokes and Benavides (2004) surveyed Chapter 13 filers in the Dallas-Fort Worth area who were participants in debt education classes from 1998 to 2001. The results were very similar to the previous study, and further support the positive effects of debtor education efforts. Again, over 80 percent of respondents in that study used the training, while 82 percent said they improved their money management skills. Thirty one percent said that "personal planning, values, goals and priorities" was the most useful section.

Stokes and Polansky (1999) studied the economic locus of control of bankruptcy debtors in South Texas. The economic locus of control is the relative degree to which an individual perceives that a reward follows from his own behavior rather than being controlled by external forces. Their study concluded that a class participant's locus of control could be shifted toward a more internal orientation, which leads to more successful financial management behavior. In a later study, deMagalhaes and Stokes (2005) surveyed Chapter 13 bankruptcy filers in Corpus Christi and Harlingen, Texas, and asked them to identify the main reasons for the financial problems that led them to declaring bankruptcy. The most important reasons identified in that study were house payment/property taxes and overspending with credit cards. It is this latter study which forms the basis for the current project.

Studies of consumer debt education in other areas of the country also suggest that education and financial counseling is very effective. Visa, International, the credit card company, conducted several studies which found that losses to creditors could be reduced via debtor education. Debtor education also improved the individuals' overall money management practices. As a result of a 1996 study, Visa implemented various processes which help identify potential cardholder bankruptcy and also screen for bankruptcy abuse. Visa (1999) later surveyed 50,000 participants in a credit counseling plan. Those who successfully completed the debt management plan handled their finances and avoided bankruptcy better than those who did not complete the plan. One year later, a Visa survey of 20,000 bankruptcy debtors found that most filers wanted additional financial education, even years after their bankruptcy filing. All of these studies show that people want more financial knowledge, and that they will use the information presented to improve their money management behaviors. This is an important finding in generating support for future financial literacy efforts.

It is also important to keep in mind recent changes in bankruptcy legislation. Amendments to the law which were passed in 2005 force some debtors to file for a Chapter 13 bankruptcy instead of a Chapter 7 by way of an economic means test. The amounts allowed for exempt assets, which are the assets that creditors are not allowed to seize, were also modified. Some limits in the homestead exemption affected states like Texas and Florida where the exemption had previously been unlimited. Most importantly for this study, legislative changes now require bankruptcy filers to participate in debtor education. 


\section{METHODOLOGY}

To explore students' attitudes and behaviors regarding consumer debt, we used a survey instrument that deals with a number of issues related to personal bankruptcy filings. This survey was nearly identical to the survey developed for the deMagalhaes and Stokes (2005) research. The questions focused primarily on the reasons for filing bankruptcy, relationships between money and happiness, and perceptions regarding the ability to handle credit. We distributed questionnaires to students of 3 business courses at Texas A\&M University - Corpus Christi in March 2006. Two of these courses were core business classes (Business Law and Financial Management). These classes are populated primarily by College Juniors. The third class was a required Finance course, Security Analysis and Portfolio Management. These students were offered five bonus points on a test to participate. Further these students were paid $\$ 15$ to defray the cost of obtaining their credit score.

The questionnaire we used was nearly identical to the one distributed to filers of Chapter 13 bankruptcy who attended mandatory 3-hour-long money management classes in 2003-2004 in Harlingen and Corpus Christi, Texas. In that study, the subjects were asked to complete the questionnaires anonymously prior to the beginning of the class. Anonymity helped individuals answer questions concerning difficult personal circumstances more candidly. Asking them to complete the questionnaires at the beginning of class guarded against the possibility of bias from class instruction or course materials. The more detailed results of the survey and a copy of the survey instrument will be provided by the authors upon request.

We used the same analysis as described in the deMagalhaes and Stokes article: Subjects were asked to use a Likert scale of 1 to 5 when answering various questions. Hence, some of the survey variables are ordinal while others are nominal or continuous, as when subjects reported their income. First we generated descriptive statistics. Second, we analyzed the data further by performing Kruskal-Wallis one-way analyses of variance. We chose this nonparametric test since much of this nominal or ordinal data are not normally distributed. This methodology is appropriate because we wished to compare groups based on demographic or ordinal variables to determine if their answers were significantly different. For example, subjects were classified in one of 6 income groups to assess whether minimum household income needed, expressed as a percentage of their current income, differed among income groups. We also analyzed responses of persons according to race/ethnicity, education, and self-rated level of training in financial skills. At the end of the survey we asked several demographic questions.

\section{RESULTS}

Demographically, approximately 55 percent of the bankruptcy filing subjects were between the ages of 40 and 59. The average age for the students sampled is 24 and the median age is 22 . While over 90 percent of the student subjects were less than 29 , they ranged in age from 19 to 57 . The majority of bankruptcy filing subjects are married (75.1 percent), though, as one might expect, the vast majority of the students are unmarried. Most of the bankruptcy subjects are high school graduates and a small minority has even completed post-graduate programs. Clearly, all of the student subjects have had "some college".

Eighty-two percent of bankruptcy subjects are Hispanic/Latin while 13.3 percent are Caucasian/White. This result was expected, since the classes were held in Corpus Christi, which has a majority Hispanic population, and in Harlingen, a predominantly Hispanic part of the Texas Rio Grande Valley. A comparison was made of the answers from Hispanic/Latin subjects in relation to those of the Caucasian/White subjects. We found no significant differences in the answers from these two groups. The vast majority ( 65 percent) of the student subjects are Caucasian. Twentyfive percent of the student subjects are Hispanic. For comparison purposes, the College of Business is made up of 58 percent Caucasian and 35 percent Hispanic students.

The mean household income for the bankruptcy filers was about $\$ 32,900$ although 32 percent of subjects earned less than $\$ 20,000$. Fifty-five percent earned $\$ 30,000$ or less annually. Students were asked what household income they expected to earn in their first year after graduation. The average was $\$ 40,798$ while the mean and mode were both $\$ 40,000$. Regarding their income, 54 percent of the bankrupt subjects thought that their level of income was low (rating it as a one or two on the Likert scale). Students generally believe that their "expected" household income 
would be satisfactory with nearly 60 percent giving it the scale's middle value of 3 .

The least amount our bankrupt subjects mentioned they need to live comfortably was an average of $\$ 44,316$ which compares to the median household income in the US, $\$ 41,994$ (U.S. Bureau of the Census. 2000). This indicates, on average, about a $\$ 12,000$ gap between actual income and the minimum income subjects perceive they need to live comfortably. The students were also asked to give a value answer to the "least amount of household income I would need to live comfortably" question. The students reported that they would, on average, need $\$ 35,320$ to live comfortably. (The median and mode value is $\$ 30,000$ ).

On average, the bankrupt subjects reported that it would take $\$ 38,770$ for a couple, with no children to live comfortably. Students reported that a couple, with no children would need at least $\$ 49,465$ to live comfortably. The median student response was $\$ 50,000$, and the mode was $\$ 50,000$.

On questions related to their attitude toward such items as happiness, and the importance of money, most bankruptcy filers were fairly happy (38 percent ranked their happiness as high in question 5), and considered money to be important to their happiness (48 percent ranked the importance of money as high in question 6). Students, however, are ecstatic! Only one student reported that their happiness was a 1, while 6.7\% rated their happiness a 2, while 59\% rated that their happiness was a 4 or 5 ! The students rate money to be an important part of their happiness, though. Fifty-six percent of the student respondents rated it a four or five on the scale.

Thirty-five percent of the bankrupt participants in responding to question 7 stated that when a person is issued a credit card, the issuer believes that person can responsibly handle that amount of credit. Since credit card debt is the second most common reason for declaring bankruptcy, this is an important finding. This finding is also noteworthy considering that approximately 25.4 percent of bankrupt respondents rated their level of training in financial skills as high while 41percent rated their financial skills as at least average.

The results of question 7 are mixed for students. In general they either agree or disagree. Few (16\%) are in the middle. Thirty-six percent of students disagreed with the statements, "If a person is issued a credit card it means the issuer believes that person can responsibly handle that amount of credit." Forty-eight percent agreed with the statement, however. The mean student rating for credit card debt is not significantly different than the mean rating by Chapter 13 filers (Mann-Whitney Test "Z" statistic: -.905 p.<.37 ). This suggests that both students and Chapter 13 filers have about the same opinion on the question of whether receiving a credit offer means that the card issuer considers the recipient capable of handling credit responsibly. We would expect that students, a group with greater confidence in their financial skills, would strongly disagree with the proposition that a card issuer considers individuals capable of handling credit responsibly when credit offers are made to them. This suggests that both students and Chapter 13 filers need counseling on the perils of credit card debt, which was identified by both groups as one of the most important causes of financial difficulties.

While 25 percent of bankruptcy filers rated their training in financial skills as high, approximately 56 percent of student respondents rated their level of training in financial skills as high in response. In fact, only $9 \%$ of students rated their financial skills as below average! The mean student rating for financial skills is 3.596 on the Likert scale of 1 to 5 , with 5 being the highest rating of financial skill. By contrast, Chapter 13 filers had a mean rating of 2.880, which is lower than the student rating and significantly different (Mann-Whitney Test "Z" statistic of -6.209 p.<.01). 
Table 1

Most Important Reasons for Money Problems Comparison of Students and Chapter 13 Filers, Shown in Percentages

\begin{tabular}{lcc}
\hline Most Important Reasons for Money Problems & Students & Chap.13 Filers \\
\hline 1) House payments/property taxes & 3.8 & 27.3 \\
2) Overspending with credit cards & 39.4 & 14.4 \\
3) Loans other than home or credit card debt & 1.9 & 6.8 \\
4) Business problems (sole proprietor/family business) & 0 & 5 \\
5) Medical or health problems & 5.8 & 10.3 \\
6) Loss of a job/loss of income from job & 3.8 & 13.2 \\
7) Legal problems & 1.0 & 2.5 \\
8) Family problems (divorce, family death, etc.) & 1.9 & 6.8 \\
9) Income taxes (I.R.S.) & 0 & 2.5 \\
10) Poor money management & 39.5 & 8.9 \\
11) Other & 2.9 & 2.3 \\
\hline Totals & $100 \%$ & $100 \%$ \\
\hline
\end{tabular}

Table 2

Top Five Most Important Reasons for Money Problems Comparison of Students and Chapter 13 Filers, Shown in Cases and Percentages

\begin{tabular}{lcc}
\hline Top 5 Most Important Reasons for Money Problems & Students & Chap.13 Filers \\
\hline House payments/property taxes & $4(4.2 \%)$ & $120(36.9 \%)$ \\
Overspending with credit cards & $41(42.7 \%)$ & $63(19.4 \%)$ \\
Medical or health problems & $6(6.3 \%)$ & $45(13.8 \%)$ \\
Loss of a job/loss of income from job & $4(4.2 \%)$ & $58(17.8 \%)$ \\
Poor money management & $41(42.7 \%)$ & $39(12.0 \%)$ \\
\hline Totals & $96(100 \%)$ & $325(100 \%)$ \\
\hline
\end{tabular}

Table 3

Top Five Most Important Reasons for Money Problems Comparison of the Caucasian and Hispanic Groups, Shown in Cases and Percentages

\begin{tabular}{lcc}
\hline Top 5 Most Important Reasons for Money Problems & Caucasian & Hispanic \\
\hline House payments/property taxes & $15(14.9 \%)$ & $101(34.6 \%)$ \\
Overspending with credit cards & $40(39.6 \%)$ & $57(19.5 \%)$ \\
Medical or health problems & $6(5.9 \%)$ & $38(13.0 \%)$ \\
Loss of a job/loss of income from job & $5(5.0 \%)$ & $54(18.5 \%)$ \\
Poor money management & $35(34.7 \%)$ & $42(14.4 \%)$ \\
\hline Totals & $101(100 \%)$ & $292(100 \%)$ \\
\hline
\end{tabular}

Participants were provided with a list of 11 factors. Bankruptcy filers were asked to pick the top three that they believed contributed to their bankruptcy. Students were asked to pick "the most important reasons you believe people have money problems". The results are quite different. Table 1 reports the results of the first choice answer by group. Table 2 lists the top five answers from each subgroup. In this case the student and the bankrupt sample each picked the same top five reasons for filing bankruptcy. However, the groups have wildly different conclusions regarding the actual cause of bankruptcy. Nearly 80 percent of students believed that the top reasons for bankruptcy were overspending with credit cards and poor money management. Only $23 \%$ of bankruptcy filers agreed that those were the top reasons for filing bankruptcy. In fact, $27.3 \%$ of the bankruptcy filers felt that house payment/property taxes were the primary cause of bankruptcy. The difference in the responses of the two groups are significant (ChiSquare: 93.04; $\mathrm{p}<.01)$. 
The samples were combined to see if there was a difference in reported reasons for bankruptcy. In Table 3 above, we compared the ranking of the five most important reasons for money problems by Caucasian and Hispanic respondents. Significant differences were noted in the responses between the groups, (Chi-Square: 50.43; p<.01). Caucasians identified overspending with credit cards and poor money management as top reasons for money problems. By contrast, Hispanics indicated that house payments and property taxes and overspending with credit cards were their top reasons. Loss of a job and medical problems were more important reasons for Hispanics than to Caucasians. The results may be influenced, however, by the relatively greater number of students in the Caucasian group. Sixty-four percent of those in the student group are Caucasians. In the Chapter 13 filer group, $83 \%$ of respondents are Hispanic and most are not students. Individuals may have identified different reasons for financial difficulties because they are at different stages in life.

An analysis of the top five reasons for money problems by the gender of the respondents did not reveal significant differences between gender groups.

\section{CONCLUSIONS}

Our goal was to investigate what students believe are the reasons people file for bankruptcy and compare them to the reasons actual bankruptcy filers cited. Bankruptcy laws have changed recently, and legislators will undoubtedly consider additional modifications in the future. Understanding why people file for bankruptcy would provide valuable information for better drafting of such legislation. The causes of bankruptcy cited by people actually in Chapter 13 bankruptcy proceedings are compared to the perceptions of the causes of bankruptcy held by current students, and the results provide an opportunity to inform the academic, business, and regulatory communities of the disparities between perception and reality.

This research has provided evidence that the beliefs of students and actual Bankruptcy filers do in fact differ. Nearly $80 \%$ of students believe that the two major causes of bankruptcy may be associated with flaws of character and ignorance or laziness (overspending with credit cards and poor financial management). Actual bankruptcy filers' responses are far more dispersed. In comparison, the top three reasons picked by bankruptcy filers accounted for only sixty percent of the responses. Those filers believed that the top reasons for filing bankruptcy were problems with house payment or property taxes, overspending with credit cards and loss of a job.

We find that students as a group are happier than the bankruptcy filers. This is not a surprise, given the relatively protected lives most students lead. They have a greater belief in their own financial abilities. Once again, the students' perceptions are based on their experiences in a somewhat sheltered environment and at an age when most individuals believe they know more than they actually do. Students did not differ from the bankruptcy filers in their belief that credit card issuers can accurately judge if a person can responsibly handle that amount of credit. This last finding casts doubt on the validity of the students' responses regarding their financial knowledge.

To the extent that students' perceptions reflect those of society and to the extent that those perceptions differ from the actual experience of those going through bankruptcy, there is an opportunity to better educate students to help them prepare for the realities of their financial lives. While financial education concentrating on the benefits and responsibility of credit cards and the virtues of proper money management (the students' perceived bankruptcy causes) is important, so too is education on the costs and benefits related to financing other assets. Specifically, home ownership has many benefits, but it has costs as well, particularly if insurance and taxes are rising. As the recent slowdown in housing sales demonstrates, neither is it a guaranteed way to make money. Just as students perceive that people can overspend with credit cards, it is not much of an extension to teach them there may also be overspending on other assets such as real estate. As pointed out by the bankruptcy filers, problems making a house payment may lead to bankruptcy.

Further, it is important to realize that an unexpected event or expense, especially if the family lacks a sufficient emergency fund, can just as easily lead to a financial catastrophe. Recent reports by the Commerce Department show that the savings rate in this country was a negative 1\% last year (Crutsinger 2007), indicating that more people than ever before are dangerously close to serious financial trouble. Secondary schools, colleges and 
universities need to be teaching students how important it is to have sufficient savings for common problems, such as divorce, illness, accidents, and job loss. Many professionals, such as bankers, brokers, lenders, accountants, lawyers, and insurance agents are in a position to recognize the danger signals in their clients' situations and help them avoid greater problems. Non-profit organizations and the media can disseminate needed information as well. Legislators have a role in regulating lenders, particularly those that take advantage of people in desperate financial straits. The findings of this study should be of interest to all of these entities.

\section{REFERENCES}

1. Clements, J., D. Johnson, K. Michelich, and C. Olinsky. 1999. Characteristics of Bankruptcy Filers: Implications for Educators. Journal of Family and Consumer Science 91(4): 71-74.

2. Crutsinger, Martin. 2007. 2006 Personal Savings Fall to 74-Yr. Low. ABC News Money, February 1. http://abcnews.go.com/Business/wireStory?id=2840706.

3. Domwitz, I., and R. Sartain. 1999. Determinants of the Consumer Bankruptcy Decision. Journal of Finance 54(1): 403-420.

4. deMagalhaes, J., and P. Stokes. 2005. Attitudes and Assets: An Investigation of the Causes of Personal Bankruptcy. Journal of Business and Economics Research 3(6): 67-77.

5. Khasru, B. 1996. Personal Bankruptcies on the Increase as Stigma Fades. Fairfield County Business Journal 35(21): 9.

6. $\quad$ Myers, D., and E. Diener. 1996. The Pursuit of Happiness. Scientific American 274 (5): 70-73.

7. Stokes, P. Moving from Bankruptcy to Solvency: An Educational Experiment that Works. Business Credit, June 1995, 20-25.

8. Stokes, P., and A. Benavides. 2004. Forces or Free Will? A Comparative Analysis of Mandatory Versus Voluntary Debtor Education. Journal of Legal, Ethical, and Regulatory Issues 7(1): 73-85.

9. Stokes, P., and S. Polansky. 1999. Shifting the Economic Locus of Control: Improving Financial DecisionMaking in High-Risk Populations. Academy of Accounting and Financial Studies Journal 3(1): 95-101.

10. U.S. Bureau of the Census. U.S. Summary: Census 2000 Profile. Prepared by the U.S. Bureau of the Census. Washington, DC, 2000.

11. Visa. 1996. Consumer Bankruptcy: Causes and Implications: Visa/Wefa White Paper. Visa.

12. Visa. 1999. Credit Counseling Debt Management Plan Analysis: Visa White Paper. Visa.

13. Visa. 2000. Life After Bankruptcy Study: Visa White Paper. Visa.

14. Warren, E., and A. Tyagi. 2003. The Two-Income Trap: Why Middle Class Mothers and Fathers are Going Broke. New York: Basic Books.

15. Watson, J. 1998. Materialism and Debt: A Study of Current Attitudes and Behaviors. Advances in Consumer Research 25(1): 203-207. 


\section{APPENDICES}

\section{Appendix A}

Descriptive Statistics, Chapter 13 Filers and Students. Percentages may not add up to 100 percent due to lack of responses to some questions.

1. Annual Household Income of Chapter 13 Filers (Actual Income)

Mean: \$32,900 Standard Deviation: \$21,893

Annual Household Income of Students (Expected Income)

Mean: $\quad \$ 40,798 \quad$ Standard Deviation: $\$ 12,582$

\begin{tabular}{cccc}
\hline Income Groups & Annual Income & Percent of Filers & Percent of Students \\
\hline 1 & $<\$ 20,000$ & $32.0 \%$ & $1 \%$ \\
2 & $\$ 20,001-\$ 30,000$ & $23.2 \%$ & $6.7 \%$ \\
3 & $\$ 30,001-\$ 40,000$ & $14.1 \%$ & $39.4 \%$ \\
4 & $\$ 40,001-\$ 50,000$ & $12.5 \%$ & $28.8 \%$ \\
5 & $\$ 50,001-\$ 60,000$ & $8.6 \%$ & $12.5 \%$ \\
6 & $\$ 60,000$ and over & $9.5 \%$ & $11.6 \%$ \\
\hline
\end{tabular}

2. How subjects rated their level of income:

Far too Low

More than Sufficient

\begin{tabular}{cccccc}
\hline Group & 1 & 2 & 3 & 4 & 5 \\
\hline Filers & $20.4 \%$ & $34.0 \%$ & $39.6 \%$ & $4.9 \%$ & $1.1 \%$ \\
\hline Students & $3.7 \%$ & $15.5 \%$ & $62.6 \%$ & $13.4 \%$ & $4.8 \%$ \\
\hline
\end{tabular}

3. The least amount subjects need to live comfortably (Chapter 13 Filers):
Mean:
$\$ 44,316$
Standard Deviation:
$\$ 25,933$

The least amount subjects need to live comfortably (Students):
Mean:
$\$ 35,320$
Standard Deviation:
$\$ 17,361$

4. The least amount a couple (with no children) need to live (Chapter 13 Filers):

Mean: $\quad \$ 38,770 \quad$ Standard Deviation: $\$ 19,869$

The least amount a couple (with no children) need to live (Students):

Mean: \$49,495 Standard Deviation: \$22,040

5. How happy subjects rated themselves:

Very Unhappy

\begin{tabular}{cccccc}
\hline Group & 1 & 2 & 3 & 4 & \multicolumn{2}{c}{ Very Happy } \\
\hline Filers & $10.2 \%$ & $14.2 \%$ & $37.5 \%$ & $21.6 \%$ & $16.6 \%$ \\
\hline Students & $1.6 \%$ & $6.7 \%$ & $32.7 \%$ & $38.5 \%$ & $21.1 \%$ \\
\hline
\end{tabular}

6. The importance of money (income or wealth) to their happiness:

Not at all Important

Very Important

\begin{tabular}{cccccc}
\hline Group & 1 & 2 & 3 & 4 & 5 \\
\hline Filers & $3.5 \%$ & $10.1 \%$ & $38.1 \%$ & $25.8 \%$ & $22.5 \%$ \\
\hline Students & $1.9 \%$ & $9.6 \%$ & $32.7 \%$ & $39.4 \%$ & $16.4 \%$ \\
\hline
\end{tabular}


7. If a person is issued a credit card it means the issuer believes that person can responsibly handle that amount of credit:

\begin{tabular}{cccccc} 
& Strongly Agree & & \multicolumn{2}{c}{ Strongly Disagree } \\
\hline Group & 1 & 2 & 3 & 4 & 5 \\
\hline Filers & $19.9 \%$ & $15.0 \%$ & $19.4 \%$ & $13.0 \%$ & $32.7 \%$ \\
\hline Students & $14.4 \%$ & $22.1 \%$ & $17.3 \%$ & $28.8 \%$ & $17.4 \%$ \\
\hline
\end{tabular}

8. Satisfaction with employment (Chapter 13 Filers only) :

Very Satisfied

\begin{tabular}{cccccc} 
& & & & & Very Dissatisfied \\
\hline Group & 1 & 2 & 3 & 4 & 5 \\
\hline Filers & $8.2 \%$ & $7.3 \%$ & $27.0 \%$ & $31.0 \%$ & $26.5 \%$ \\
\hline
\end{tabular}

9. Ranking of level of training in financial skills:

\begin{tabular}{cccccc} 
& Very Low & & & \multicolumn{2}{c}{ Very High } \\
\hline Group & 1 & 2 & 3 & 4 & 5 \\
\hline Filers & $11.5 \%$ & $23.4 \%$ & $39.6 \%$ & $16.4 \%$ & $9.0 \%$ \\
\hline Students & $1.9 \%$ & $8.7 \%$ & $33.7 \%$ & $39.4 \%$ & $16.3 \%$ \\
\hline
\end{tabular}

10. Top three most important reasons for the subjects' money problems:

Comparison of Students and Chapter 13 Filers, Shown in Percentages

\begin{tabular}{lcc}
\hline Most Important Reasons for Money Problems & Students & Chap.13 Filers \\
\hline 1) House payments/property taxes & 3.8 & 27.3 \\
2) Overspending with credit cards & 39.4 & 14.4 \\
3) Loans other than home or credit card debt & 1.9 & 6.8 \\
4) Business problems (sole proprietor/family business) & 0 & 5 \\
5) Medical or health problems & 5.8 & 10.3 \\
6) Loss of a job/loss of income from job & 3.8 & 13.2 \\
7) Legal problems & 1.0 & 2.5 \\
8) Family problems (divorce, family death, etc.) & 1.9 & 6.8 \\
9) Income taxes (I.R.S.) & 0 & 2.5 \\
10) Poor money management & 39.5 & 8.9 \\
11) Other & 2.9 & 2.3 \\
\hline Totals & $100 \%$ & $100 \%$ \\
\hline
\end{tabular}

Top Five Most Important Reasons for Money Problems: Comparison of Students and Chapter 13 Filers, Shown in Cases and Percentages.

\begin{tabular}{lcc}
\hline Top 5 Most Important Reasons for Money Problems & Students & Chap.13 Filers \\
\hline House payments/property taxes & $4(4.2 \%)$ & $120(36.9 \%)$ \\
Overspending with credit cards & $41(42.7 \%)$ & $63(19.4 \%)$ \\
Medical or health problems & $6(6.3 \%)$ & $45(13.8 \%)$ \\
Loss of a job/loss of income from job & $4(4.2 \%)$ & $58(17.8 \%)$ \\
Poor money management & $41(42.7 \%)$ & $39(12.0 \%)$ \\
\hline Totals & $96(100 \%)$ & $325(100 \%)$ \\
\hline
\end{tabular}




\section{Gender:}

Chapter 13 Filers: Male 48.8\%, Female 51.2\%

Students: Male 49\%, Female 51\%

12. Race/ethnicity

\begin{tabular}{lcc}
\hline Race Ethnicity & Percent of Filers & Percent of Students \\
\hline African American / Black & $2.0 \%$ & $2.9 \%$ \\
Caucasian / White & 13.3 & 64.8 \\
Native American & 0.4 & 1.0 \\
Asian & 0.9 & 2.9 \\
Hispanic / Latin & 82.7 & 24.7 \\
Other & 0.7 & 3.7 \\
\hline
\end{tabular}

Top Five Most Important Reasons for Money Problems: Comparison of the Caucasian and Hispanic Groups, Shown in Cases and Percentages.

\begin{tabular}{lcc}
\hline $\begin{array}{l}\text { Top } 5 \text { Most Important Reasons for } \\
\text { Money Problems }\end{array}$ & Caucasian & Hispanic \\
\hline House payments/property taxes & $15(14.9 \%)$ & $101(34.6 \%)$ \\
Overspending with credit cards & $40(39.6 \%)$ & $57(19.5 \%)$ \\
Medical or health problems & $6(5.9 \%)$ & $38(13.0 \%)$ \\
Loss of a job/loss of income from job & $5(5.0 \%)$ & $54(18.5 \%)$ \\
Poor money management & $35(34.7 \%)$ & $42(14.4 \%)$ \\
\hline Totals & $101(100 \%)$ & $292(100 \%)$ \\
\hline
\end{tabular}

\section{Appendix B}

Descriptive Statistics for the students sampled. Percentages may not add up to 100 percent due to lack of responses to some questions.

\begin{tabular}{|c|c|c|c|}
\hline & Sample & \multicolumn{2}{|l|}{ College } \\
\hline Age & & & \\
\hline Average & 23.98 & \multicolumn{2}{|l|}{24.8} \\
\hline Median & \multicolumn{3}{|l|}{22} \\
\hline Sex & count & \multicolumn{2}{|l|}{$\%$} \\
\hline Male & 52 & \multicolumn{2}{|l|}{49.52} \\
\hline Female & 53 & \multicolumn{2}{|l|}{50.48} \\
\hline \multicolumn{3}{|c|}{ Average number of Credit Cards } & 2.46 \\
\hline \multirow{2}{*}{\multicolumn{3}{|c|}{$\begin{array}{l}\text { Avg. Credit Card Balance (all) } \\
\text { Avg. Credit Card Balance (non-zero) }\end{array}$}} & $\$ 1,076$ \\
\hline & & & $\$ 2,747$ \\
\hline \multirow{2}{*}{\multicolumn{3}{|c|}{$\begin{array}{l}\text { Avg. Student Loan Balance (all) } \\
\text { Avg. Student Loan Balance (non-zero) }\end{array}$}} & $\$ 7,689$ \\
\hline & & & $\$ 13,555$ \\
\hline \multicolumn{3}{|c|}{ Avg. Car Loan (all) } & $\$ 2,974$ \\
\hline \multicolumn{3}{|c|}{ Avg. Car Loan (non-zero) } & $\$ 10,940$ \\
\hline
\end{tabular}


First Full Year 'Expected' Income

Average

$\$ 40,798$

Median $\$ \$ 0,000$

Mode $\$ 40,000$

Standard Deviation $\$ 12,683$

Minimum $\$ 18,000$

Maximum $\$ 80,000$

Least Student would need to live 'Comfortably'

Average

$\$ 35,320$

Median

$\$ 30,000$

Mode

$\$ 30,000$

Standard Deviation

$\$ 17,361$

Minimum

$\$ 6,000$

Maximum

$\$ 150,000$

Major:

Finance 41

Accounting

11

Management

22

Marketing

06

General Business

14

Other

13

NOTES 
NOTES 